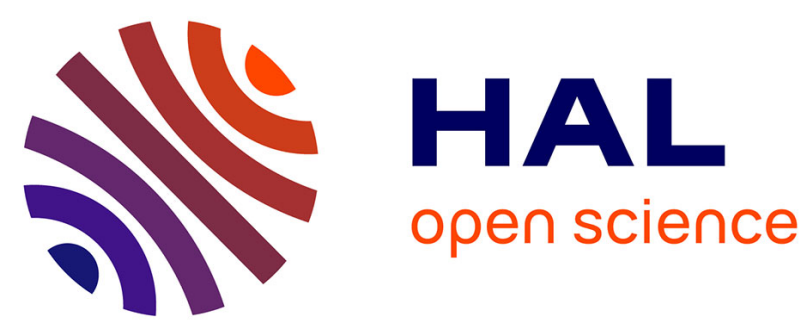

\title{
Transcriptional explorations of CAPN3 identify novel splicing mutations, a large-sized genomic deletion and evidence for messenger RNA decay
}

M Krahn, C Pécheux, F. Chapon, Christophe Béroud, V Drouin-Garraud, P Laforet, N Romero, I. Penisson-Besnier, R. Bernard, J A Urtizberea, et al.

\section{To cite this version:}

M Krahn, C Pécheux, F. Chapon, Christophe Béroud, V Drouin-Garraud, et al.. Transcriptional explorations of CAPN3 identify novel splicing mutations, a large-sized genomic deletion and evidence for messenger RNA decay. Clinical Genetics, 2007, 72 (6), pp.582 - 592 . 10.1111/j.13990004.2007.00906.x . hal-01681861

\section{HAL Id: hal-01681861 \\ https: / hal-amu.archives-ouvertes.fr/hal-01681861}

Submitted on 11 Jan 2018

HAL is a multi-disciplinary open access archive for the deposit and dissemination of scientific research documents, whether they are published or not. The documents may come from teaching and research institutions in France or abroad, or from public or private research centers.
L'archive ouverte pluridisciplinaire HAL, est destinée au dépôt et à la diffusion de documents scientifiques de niveau recherche, publiés ou non, émanant des établissements d'enseignement et de recherche français ou étrangers, des laboratoires publics ou privés. 


\section{Short Report}

\section{Transcriptional explorations of $C A P N 3$ identify novel splicing mutations, a large-sized genomic deletion and evidence for messenger RNA decay}

Krahn M, Pécheux C, Chapon F, Béroud C, Drouin-Garraud V, Laforet P, Romero NB, Penisson-Besnier I, Bernard R, Urtizberea JA, Leturcq $\mathrm{F}$, Lévy N. Transcriptional explorations of $C A P N 3$ identify novel splicing mutations, a large-sized genomic deletion and evidence for messenger RNA decay.

Clin Genet 2007: 72: 582-592. (C) Blackwell Munksgaard, 2007

Mutations in the gene encoding calpain-3 (CAPN3) cause autosomal recessive limb-girdle muscular dystrophy type $2 \mathrm{~A}$ (LGMD2A) and idiopathic eosinophilic myositis. Accurate diagnosis and genetic counselling are based on the identification of disease-causing mutations on both alleles of CAPN3 in the patients. In the present study, we used transcriptional analysis as a complementary approach for patients suspected of being affected with LGMD2A, in whom initial denaturing high-performance liquid chromatography genomic mutation screening evidenced no or only one $C A P N 3$ mutation obviously considered as disease causing. This allowed to identify and characterize cDNA deletions. Further genomic analysis allowed to determine the origin of these deletions, either as splicing defects caused by intronic mutations or as an internal multi-exonic deletion. In particular, we report two novel CAPN3 mutations (c.1745 + 4_1745 + 7delAGTG in IVS13 and c.2185$16 \mathrm{~A}>\mathrm{G}$ in IVS20) and a recurrent large-sized genomic deletion including exons 2-8 for which genomic breakpoints have been characterized. In addition, our results indicate nonsense-mediated messenger RNA decay as a mechanism for under-expression of $C A P N 3$ associated to some specific variations.

\author{
M Krahn ${ }^{a *}$, C Pécheux ${ }^{a *}$, \\ F Chapon ${ }^{\mathrm{b}}$, C Béroud ${ }^{\mathrm{c}}$, \\ V Drouin-Garraud ${ }^{\mathrm{d}}, \mathrm{P}_{\text {Laforet }}{ }^{\mathrm{e}}$, \\ NB Romerof, I Penisson-Besnier ${ }^{g}$, \\ R Bernard ${ }^{\mathrm{a}}$, JA Urtizberea ${ }^{\mathrm{h}}$, \\ $F$ Leturcq and $N$ Lévy ${ }^{a, j}$
}

${ }^{a}$ Département de Génétique Médicale, Hôpital d'enfants de la Timone, Marseille, France, ${ }^{b}$ Consultation de Pathologies neuromusculaires and Laboratoire de Neuropathologie, CHU Cote de Nacre, Caen, France, ' INSERM U827 - Génétique des maladies rares: pathologie moléculaire, études fonctionnelles, banque de données génétiques, Institut Universitaire de Recherche Clinique, Montpellier, France, dService de Génétique, Hôpital Charles Nicolle, Rouen, France, ${ }^{e}$ Institut de Myologie and ${ }^{\mathrm{f}}$ INSERM U582 Institut de Myologie, Hôpital de la Pitié-Salpétrière, Paris, France, 'Département de Neurologie, $\mathrm{CHU}$, Angers, France, hAPHP, Hôpital Marin d'Hendaye, Hendaye, France, 'Laboratoire de Biochimie Génétique, Hôpital Cochin, Paris, France, and IINSERM

U491, équipe: 'Génétique des maladies neuromusculaires et des Laminopathies', Faculté de Médecine de Marseille, France

*These authors contributed equally to this work.

Key words: calpain-3 - calpainopathy CAPN3 - deletion - intronic variant LGMD2A - NMD - RT-PCR

Corresponding author: Professor Nicolas Lévy, Département de Génétique Médicale, Hôpital d'enfants de la Timone, 264 rue Saint-Pierre, 13385 Marseille Cedex 5, France.

Tel.: + 334913877 87;

fax: +334913846 76;

e-mail: nicolas.levy@medecine.univ-mrs.fr

Received 11 June 2007, revised and accepted for publication 16 August 2007 


\section{Introduction}

Autosomal recessive limb-girdle muscular dystrophy type 2A (LGMD2A, MIM \#253600) and idiopathic eosinophilic myositis are caused by mutations in the gene encoding calpain-3 (CAPN3; $15 q 15.1-15.3)(1-3)$. Calpain-3 is a non-lysosomal protease mainly expressed in skeletal muscle (4), where it appears to play a central role in sarcomere remodelling $(5,6)$.

LGMD2A is the most prevalent autosomal recessive LGMD (LGMD2; 10-30\%) (7-9). As there is a high clinical variability in patients affected with LGMD2A, calpain-3 protein determination on muscle samples is performed at first instance to orientate diagnosis. However, $C A P N 3$ mutation analysis is necessary for accurate diagnosis and genetic counselling. Genomic denaturing high-performance liquid chromatography (DHPLC) analysis is particularly adapted for this purpose because of the relatively large size of the gene (24 exons) and the increasing number of reported allelic variants (more than 350 different variants collected in the Leiden Muscular Dystrophy pages database, www.dmd.nl) (10). Unfortunately, in $20-30 \%$ of patients, routine genomic analysis fails to identify both disease-causing alleles $(10-13)$. These patients should benefit from complementary approaches towards completing the mutation's identification.

Here, we performed transcriptional analyses in five patients suspected of being affected with LGMD2A, in whom initial DHPLC/genomic mutation screening evidenced no or a single-allele $C A P N 3$ disease-causing mutation thus not sufficient to firmly confirm diagnosis.

\section{Patients, materials and methods}

Patients: inclusion criteria and tissue processing

In the present study, we included five patients for transcriptional analysis of $C A P N 3$. Inclusion criteria were (i) diagnosis of LGMD2A suspected on clinical indications of LGMD2, together with a marked decrease or absence of calpain-3 on muscle Western blot analysis; (ii) CAPN3 genomic mutational screening, identified only one or no mutation clearly identifiable as disease causing (i.e. previously reported as disease causing in the literature or Leiden Muscular Dystrophy pages database, Table 1); and (iii) availability of muscle biopsy samples for transcriptional analysis.

After informed consent, genomic DNA and total RNA were extracted, respectively, from peripheral blood and from frozen muscle tissue obtained from all patients. Approval was obtained from the ethics committees of the institutions involved.

\section{Genomic mutation screening}

The 24 exons and flanking intronic boundaries of $C A P N 3$ were polymerase chain reaction (PCR) amplified, and then analysed using DHPLC as previously described $(3,10)$.

RNA isolation, complementary DNA preparation, RT-PCR and long-range RT-PCR

Total RNA was extracted from frozen muscle samples with TriPure Isolation Reagent ${ }^{\circledR}$ (Roche, Indianapolis, IN) and reverse transcribed using Superscript II $^{\circledR}$ reverse-transcriptase (Invitrogen, Carlsbad, CA) according to the manufacturer's recommendations. The CAPN3 complementary DNA (cDNA) coding region was PCR amplified in five overlapping fragments using specifically designed primer pairs (Table $\mathrm{S} 1$, conditions and primer sequences available as supplementary material online). Long-range reverse transcriptase-polymerase chain reaction (RT-PCR), covering the coding sequence of exons 1-10, was performed for patient $\mathrm{CT} 5$ using primer pairs forward 5'-GCATGCTGCTGGTAGGAGAC-3' / reverse 5'-CTGAGGGTTGGTCCAGAAAG-3' (respectively RT1F and RT3R, supplementary material online), with the Expand Long Template PCR System ${ }^{\circledR}$ (Roche) according to the manufacturer's recommendations. RT-PCR products were separated and visualized under ultraviolet light by electrophoresis on $1 \%$ agarose gels stained with ethidium bromide.

\section{Bio-informatic analysis}

Possible deleterious effects of the identified intronic variants on acceptor splice sites, donor splice sites or splicing branch points were analysed using the Splice Site Finder prediction algorithm (www.UMD.be/SSF). Sorting intolerant from tolerant (SIFT) analysis was done to assess the pathogenicity of the novel missense mutation identified in patient CT1, as described (blocks. fhcrc.org/sift/SIFT.html).

\section{Real-time quantitative RT-PCR}

An expression study was performed for patients CT3 and CT4, using two TaqMan ${ }^{\circledR}$ Gene Expression Assays (Applied Biosystems, Foster City, CA): CAPN3 (Assay ID: Hs 00181057_m1)

and GAPDH (Assay ID: $99999905 \mathrm{m1} \overline{)}$ as endogenous expression control. A relative quantification plate was loaded in triplicate with 


\section{Krahn et al.}

patient cDNA samples, a normal muscle cDNA sample and a no-template control following the manufacturer's recommendations, and run on a ABI 7500 Real Time PCR System ${ }^{\circledR}$ (Applied Biosystems). Expression levels were obtained by the quantification relative study method, using the normal muscle cDNA sample as calibrator.

\section{DNA and cDNA sequencing}

PCR and RT-PCR products were purified using Montage PCR purification Kit ${ }^{\circledR}$ (Millipore, Bedford, MA). For patient CT5, individual long-range RT-PCR bands were gel purified using DNA gel extraction $\mathrm{Kit}^{\circledR}$ (Millipore).

PCR and RT-PCR products were sequenced on both strands by use of a terminator procedure, loading on ABI 3130xl Genetic Analyzer ${ }^{B}$ (Applied Biosystems), and analysis using the SEQUENCHER ${ }^{\circledR}$ software (Geno Codes Corporation, Ann Arbor, MI) with comparison to the human $C A P N 3$ gene sequence (g.DNA \# AF209502.1, c.DNA \# NM_000070).

Real-time quantitative PCR

A TaqMan ${ }^{\circledR}$ assay (Applied Biosystems) including 5'FAM-TGACATGTACAAGATCAT-3' MGBNFQ as a probe, forward primer 5'-TTTTGAGATCAGGGATGCTCCTA-3' and reverse primer 5' -AGCCTCTCTCGATGGCTTTCTT-3' was designed with PRIMER EXPRESS ${ }^{\circledR}$ software (Applied Biosystems) to amplify a $65 \mathrm{bp}$ amplicon and analyse a target sequence within exon 5 of $C A P N 3$. The human serum albumin gene $(A L B)$ was used as an internal reference for genomic gene dosage (14).

We carried out multiplex runs in quadruplicate from patient samples, control samples and notemplate controls, together with a diploid control for calibration and establishing the comparative threshold cycle curve (ddCT). All reactions were run in 96-well optical plates on a ABI 7500 Real Time PCR System ${ }^{\circledR}$ (Applied Biosystems), using the TaqMan ${ }^{\circledR}$ Universal PCR Protocol and Master mix (Applied Biosystems) according to the manufacturer's recommendations.

Data were analysed with the ABI Prism sequence detection system ${ }^{\circledR}$ (Applied Biosystems) and Microsoft Excel ${ }^{\circledR}$ software (Microsoft, Redmonton, WA). We used the comparative cycle threshold (CT) number method (15) to quantitate the relative copy number $\left(2^{-(\mathrm{ddCT} \pm \mathrm{SD})}\right)$ of the genomic target region $(C A P N 3$ exon 5) of each unknown sample, relative to the known copy number of the calibrator sample, with
$\mathrm{ddCT}=>[\mathrm{dCt} A L B-\mathrm{dCTC} A P N 3]_{\text {calibrator sample }}-$ $[\mathrm{dCt} A L B-\mathrm{dCTC} A P N 3]_{\text {unknown }}$ sample. The $\mathrm{ddCT}$ ratios are expected to be close to 1.0 for samples containing two copies of the CAPN3 genomic target region and close to 0.5 for samples with a hemizygous $C A P N 3$ allele.

\section{Results and discussion}

We used transcriptional analysis in five patients suspected of being affected with LGMD2A, in whom initial DHPLC/genomic mutation screening evidenced no or only one $C A P N 3$ mutation clearly considered as disease causing. Clinical, muscle biopsy and genomic mutational findings of all patients are presented in Table 1 .

Molecular findings in patients CT1, CT2, CT3 and CT4: the intronic variants c.2185-16A>G, C. $1745+4 \_1745$ + 7delAGTG and c.802-9G $>$ A cause abnormal splicing of the CAPN3 messenger RNA

\section{Patient CT1}

Genomic mutation screening identified a novel missense mutation (c.1259C $>$ A; p.Ala420Asp, exon 10, not found in 200 control chromosomes), predicted as non-tolerant substitution using SIFT analysis (SIFT score 0.01). In addition, a novel intronic variant, c.2185-16A $>\mathrm{G}$ (IVS20) (Table 1 and Fig. S1, supplementary material online), was identified. Both mutations have also been identified in the two symptomatic sisters of the patient (16).

cDNA analysis confirmed the missense change (r.1259C $>\mathrm{A})$ and identified a deleterious effect of c.2185-16A $>\mathrm{G}$ : a heterozygous in-frame insertion of $15 \mathrm{bp}$ from IVS20 located immediately $5^{\prime}$ from the splice acceptor site (Table 2), and predicted to cause an insertion of five amino acids (p.Gln728_Lys729insIlePheTyrCysGln) in domain IV of calpain-3 (implicated in calcium binding and homo-dimerization (17)). In regard to the complete absence of calpain-3 on Western blot analysis, we conclude that this amino acid insertion destabilizes the protein. To our knowledge, this constitutes the first reported case of an isolated calpain-3 amino acid insertion.

\section{Patient CT2}

At the genomic level, a novel $4 \mathrm{bp}$ intronic deletion in IVS13, c. $1745+41745+7$ delAGTG, was found, together with c. $\overline{17} 46-20 \mathrm{C}>\mathrm{G}(10,12$, 16, 18) (Table 1 and Fig. S1, supplementary material online).

cDNA analysis evidenced the deleterious effect of c.1745 + 4_1745 + 7delAGTG as an in-frame 
Transcriptional explorations of $C A P N 3$

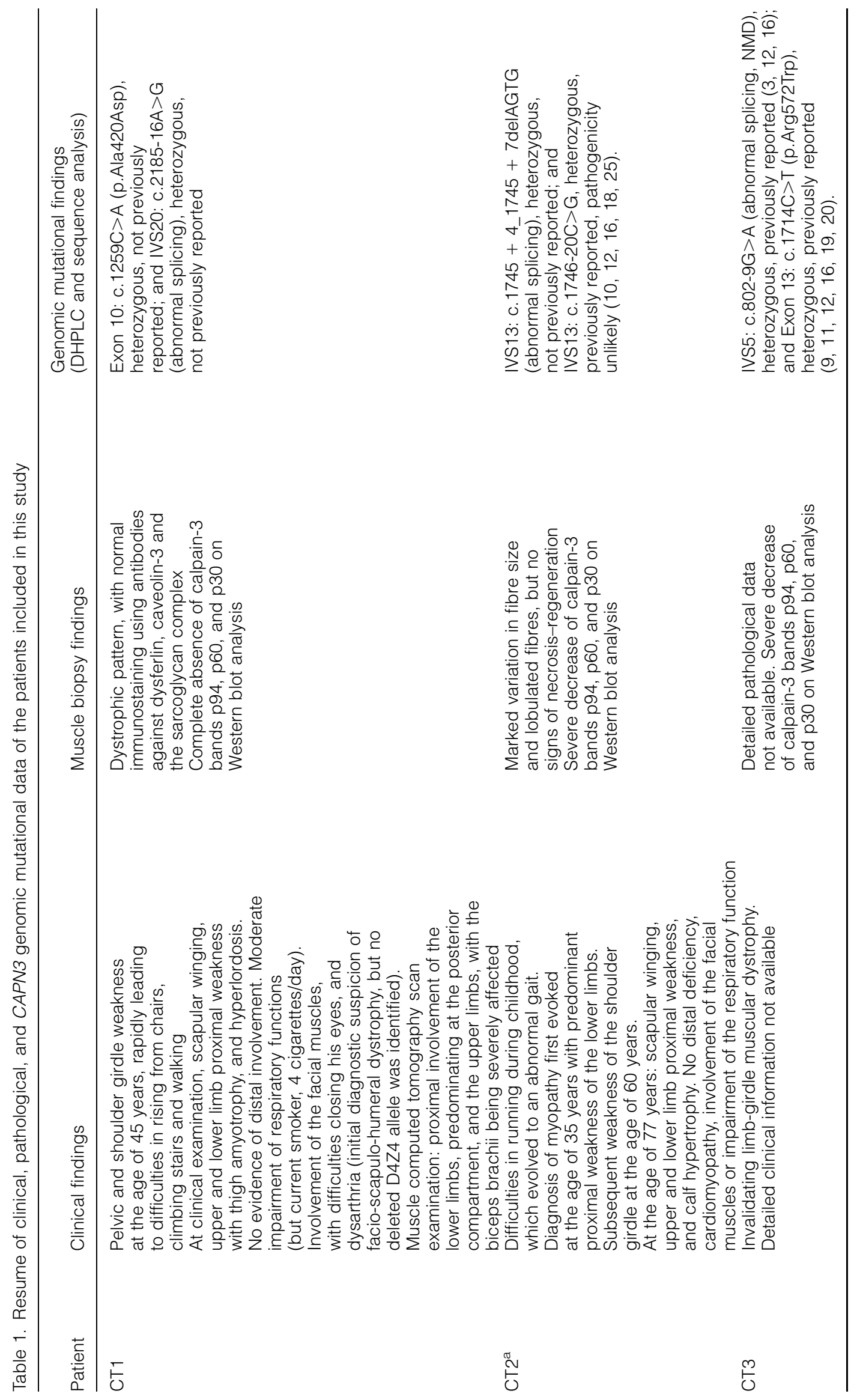


Krahn et al.

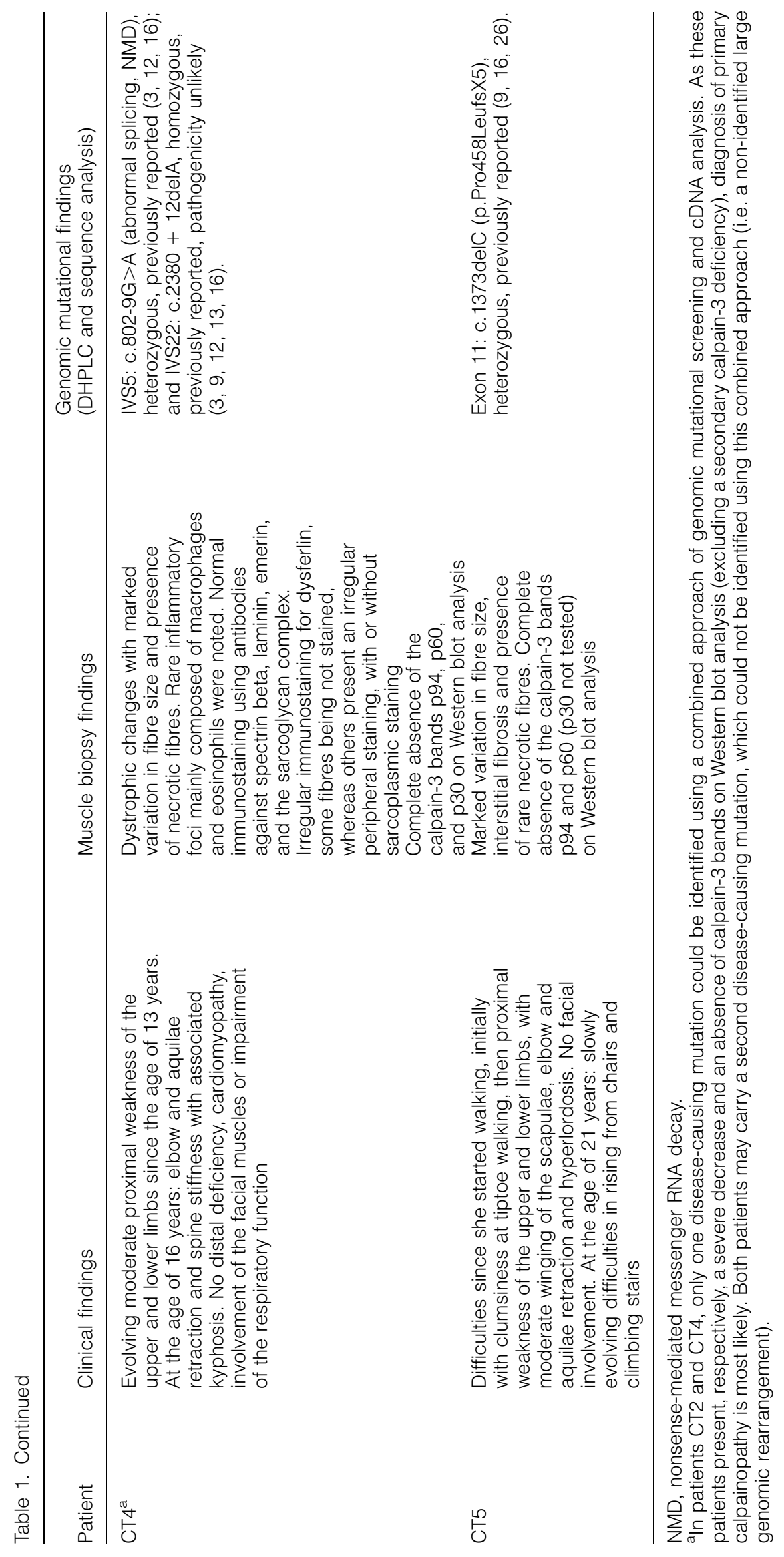


(a)

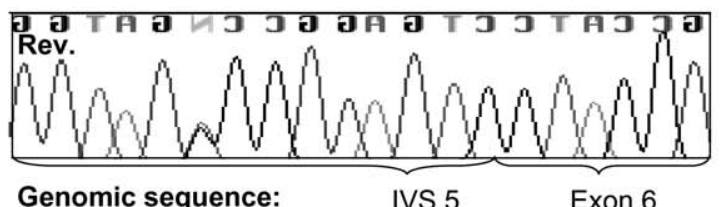

IVS 5: c.802-9G >A, heterozygous

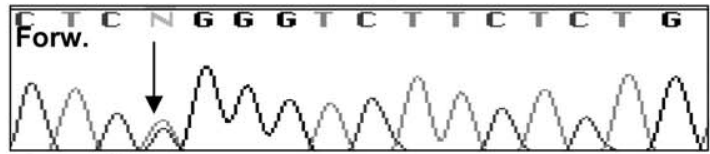

Genomic sequence:

Exon 13: c.1714C>T, heterozygous

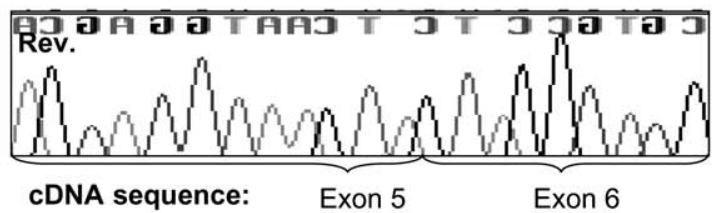

Wild-type at the junction exon 5-exon 6

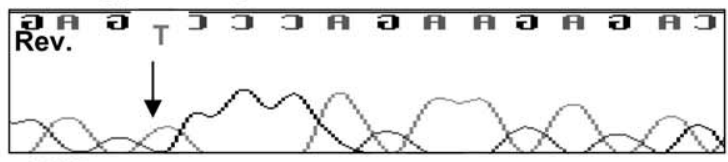

cDNA sequence:

r.1714c>u, Pseudo-homozygous
Exon13

(b)

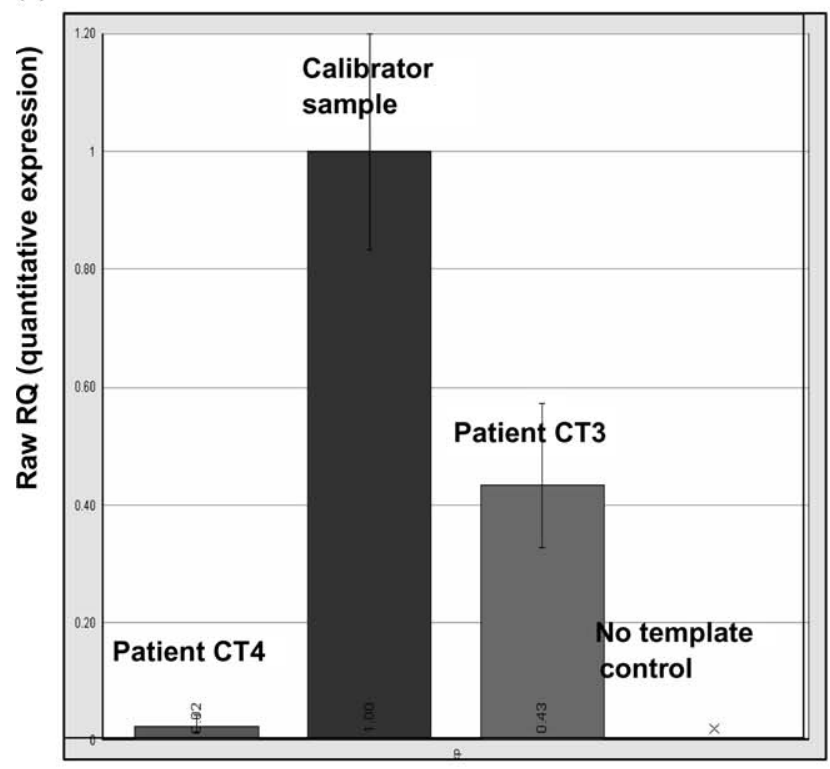

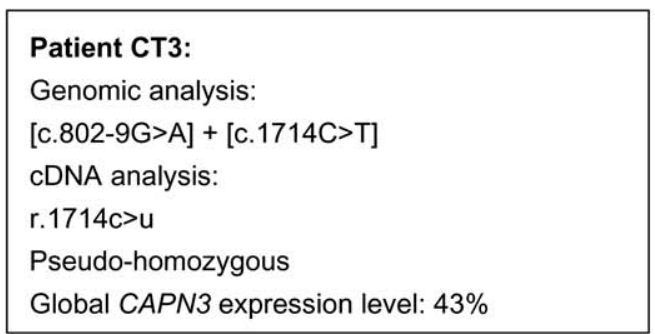

Patient CT4:

Genomic analysis:

[c.802-9G>A] + [?]

cDNA analysis:

r.801_802ins802-7_802-1

Pseudo-homozygous

Global CAPN3 expression level: $1 \%$

(c)

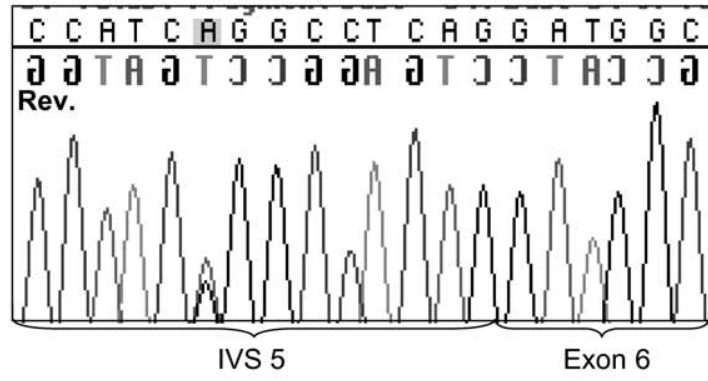

Genomic sequence:

IVS 5: c.802-9G >A, heterozygous

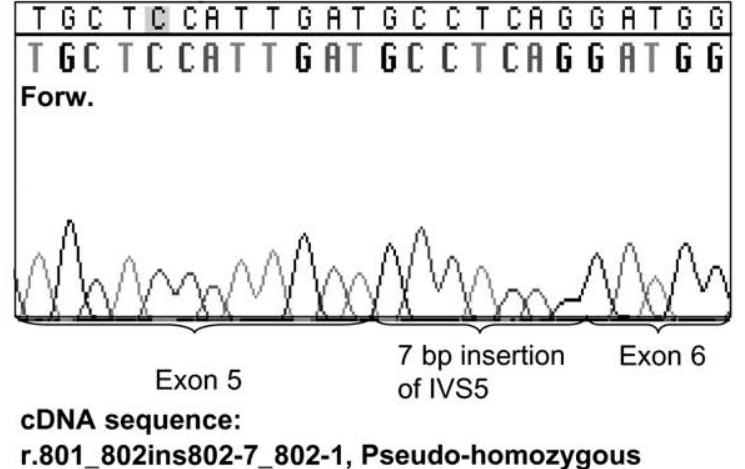

Fig. 1. Analysis of the deleterious effect caused by the c.802-9G $>$ A mutation evokes nonsense-mediated messenger RNA decay. (a) Genomic and complementary DNA (cDNA) sequence analysis in patient CT3. (b) Global CAPN3 expression analysis in patients CT3 and CT4 using quantitative reverse transcriptase-polymerase chain reaction. (c) Genomic and cDNA sequence analysis in patient CT4. Forw., forward sequence; Rev., reverse sequence.

deletion, removing $87 \mathrm{bp}$ from the terminal $3^{\prime}$ part of exon 13, possibly by activating a cryptic splice site. This is predicted to delete 29 amino acids (p.Tyr554_Glu582del) in domain III of calpain-3.
A possible deleterious effect of c.1746-20C $>$ G has been initially evoked $(12,16)$. In patient CT2, cDNA analysis did not show any sequence variation in the region of exon 14 (i.e. insertions and/or deletions), which could have resulted from 


\section{Krahn et al.}

abnormal splicing possibly caused by this variant (data not shown). This is concordant with recent data (18) and argues against a deleterious effect.

\section{Patients CT3 and CT4}

In both patients CT3 and CT4, genomic analysis identified the mutation c.802-9G $>$ A (IVS5) at a heterozygous state (Table 2).

In patient CT3, a missense mutation (exon 13: c.1714C $>$ T; p.Arg572Trp) $(9,11,12,16,19,20)$ was identified in trans. Whereas patient CT3 is compound heterozygous [c.802-9G $>\mathrm{A}]+$ $[\mathrm{c} .1714 \mathrm{C}>\mathrm{T}]$ at the genomic level, cDNA analysis retrieved only the c. $1714 \mathrm{C}>\mathrm{T}$ mutation (pseudohomozygous state) (Fig. 1a). Therefore, c.802$9 \mathrm{G}>\mathrm{A}$ may cause nonsense-mediated messenger (mRNA) decay (NMD) or a linked phenomenon in this patient because pseudo-homozygous mutations at the mRNA level as compared with the genomic findings may evoke this mechanism (21). According to a mono-allelic expression, quantitative reverse transcriptase-polymerase chain reaction (QRT-PCR) with a TaqMan $^{\circledR}$ probe showed a global level of expression of $43 \%$ (Fig. 1b). NMD has recently been shown to occur for nonsense and frameshift CAPN3 mutations (18). We here show the possible existence of NMD caused by an intronic variant, most likely by causing abnormal splicing and subsequent introduction of a premature termination codon.

In patient $\mathrm{CT} 4$, the c.802-9G $>\mathrm{A}$ mutation was found heterozygous. In addition, the c. $2380+12$ delA variant (16) was found at a homozygous state, without any qualitative effect at the cDNA level (no sequence variation in the region of exons 22 and 23).

Surprisingly, the effect of the c.802-9G $>$ A variant in patient CT4 differed from the findings in patient CT3: we observed a pseudo-homozygous insertion of $7 \mathrm{bp}$ from IVS5 located immediately $5^{\prime}$ from the splice acceptor site (Fig. 1c), most likely because of the activation of a cryptic splice acceptor site. This causes a frameshift introducing a premature translation stop codon $>50$ nucleotides upstream of the last exon-exon junction and thus candidate for NMD (22). QRTPCR with a TaqMan ${ }^{\circledR}$ probe showed a global level of expression reduced to $1 \%$ (Fig. 1b). Therefore, the pseudo-homozygous r.801_802ins802-7_802-1 insertion in patient CT4 could be related to a non-identified mutation in trans, leading to a 'complete' absence of the resulting mRNA (i.e. a non-identified large genomic rearrangement, mutations in the promoter region, etc.). This would explain that, even if the majority of mRNA originating from the c.802-9G $>\mathrm{A}$ allele is subject to NMD, a residual amount of r.801_802ins 802-7_802-1 mRNA is observed in this patient.
In addition, the different findings in patients CT3 and CT4 could be partially caused by interindividual variation in NMD efficiency $(23,24)$, related to yet unexplained genetic modifying factors.

\section{Bio-informatic splice site analysis}

All intronic variants identified in this study were analysed using Splice Site Finder, a novel algorithm for the prediction of deleterious effects on normal splicing. All bio-informatic predictions are concordant with the results of cDNA analysis (Table 2 and Fig. 3a).

Molecular findings in patient CT5: characterization of a large-sized genomic deletion including exons 2-8

Genomic DHPLC screening identified a heterozygous frameshifting mutation in exon 11 (c.1373 delC) (Table 1), but no additional variant. Accordingly, this mutation was retrieved heterozygous in her mother, whereas no mutation was identified in her father (non-paternity excluded using microsatellite analysis). cDNA analysis retrieved the c.1373delC mutation but no additional sequence variant.

To test the hypothesis of a large-sized deletion or abnormal splicing pattern, we used long-range RT-PCR with a set of primers amplifying the entire cDNA (data not shown) and a set amplifying exons 1-10, which amplified three bands (Fig. 2a): one of the expected size $(\sim 1650 \mathrm{bp})$ and two additional bands of $\sim 850$ and $\sim 550 \mathrm{bp}$. Sequencing of the additional bands after gel purification (Fig. 2a) showed two abnormal transcripts: (i) one with a deletion from exons $2-8$ (r.310_1115del, p.Glu104_Arg372delfsX11, deletion of $806 \mathrm{bp}$, corresponding to the band of $\sim 850 \mathrm{bp}=\sim 1650 \mathrm{bp}-806 \mathrm{bp}$ ) and (ii) a second with the same deletion and, in addition, a deletion of $321 \mathrm{bp}$ within exon 1, flanked by a $5^{\prime}-\mathrm{GT}$ dinucleotide, a 3'-AG dinucleotide, including $52 \mathrm{bp}$ of the $5^{\prime}$ UTR and the initial 269 coding base pairs of exon 1 ([r.-52_269del; r.310_1115del] corresponding to the band of $\sim 550 \mathrm{bp}=\sim 1650$ bp $-806 \mathrm{bp}-321 \mathrm{bp}$ ).

The large-sized genomic deletion including exons 2-8 (r.310_1115del, Fig. 3b) has been previously reported (Fig. 3c) $(16,27,28)$ but not characterized at the genomic level.

Therefore, we next used genomic quantitative PCR with a TaqMan ${ }^{\circledR}$ probe located in exon 5 (Fig. 2b). In a diploid control population of four healthy male and five healthy female individuals, 
Transcriptional explorations of $C A P N 3$

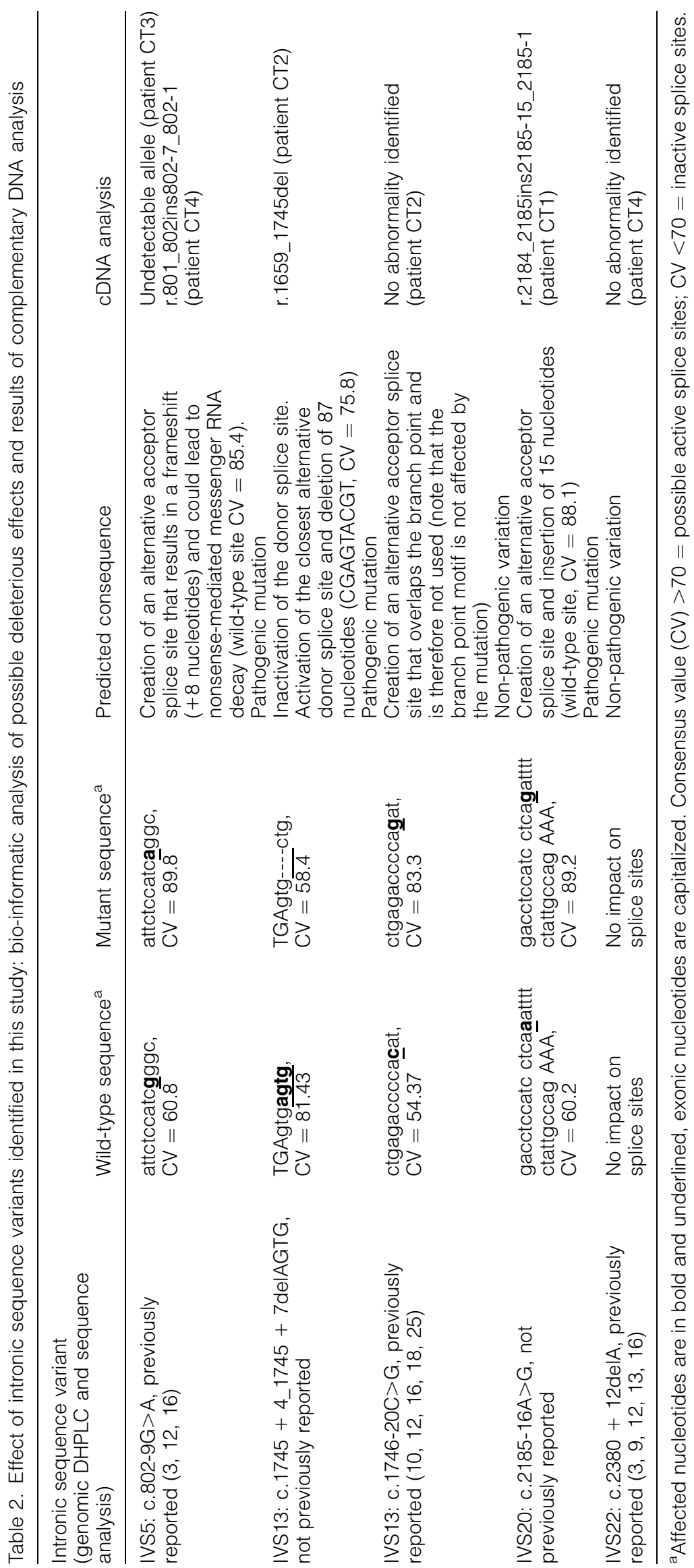




\section{Krahn et al.}

(a)

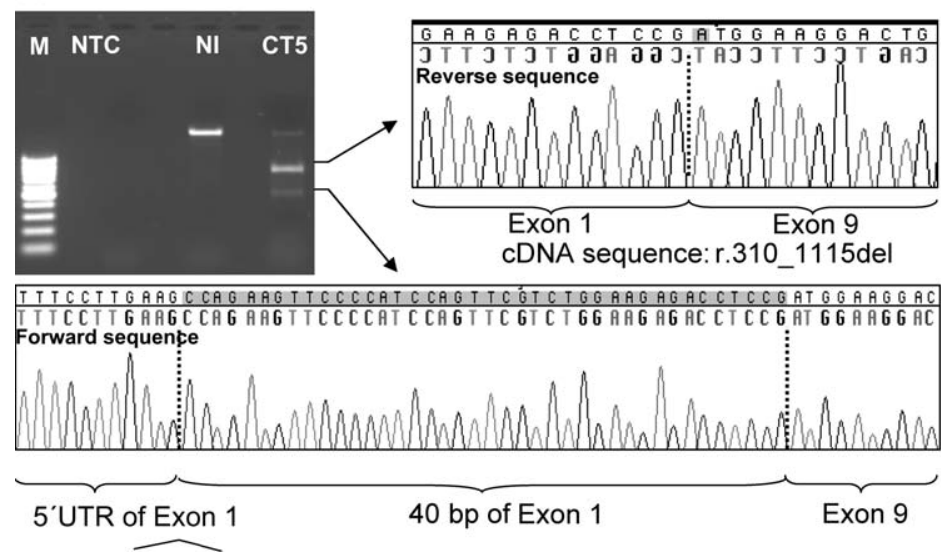

(b)

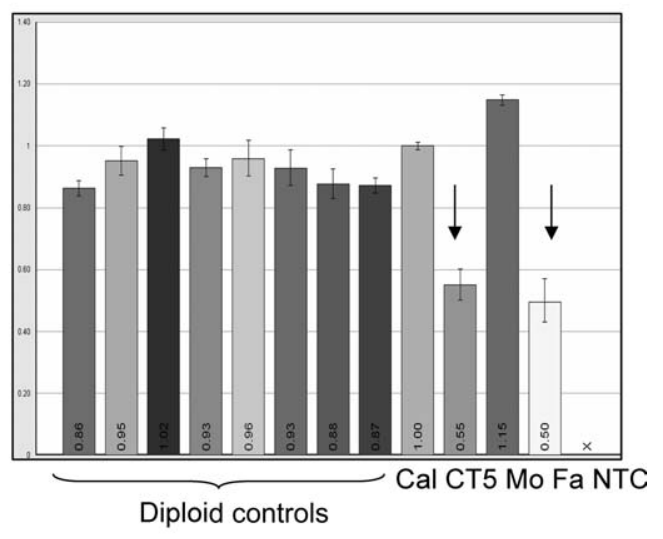

$321 \mathrm{bp}$ deletion in exon 1 , including 52 bp of the $5^{\prime}$ UTR and the initial 269 coding base pairs of exon 1 cDNA sequence: [r.-52_269del; r.310_1115del]

(c)

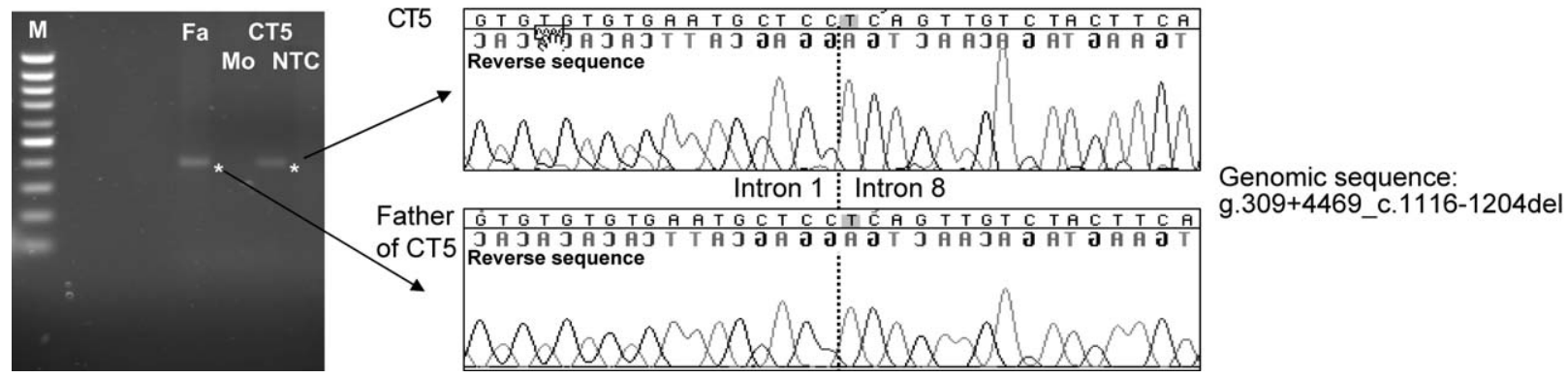

Fig. 2. Characterization of a $C A P N 3$ large-sized genomic deletion including exons 2-8. (a) Long-range reverse transcriptasepolymerase chain reaction using primers RT1F and RT3R, and sequencing of the two additional bands (arrows) in patient CT5, revealing a deletion of exons 2-8. (b) Genomic quantitative polymerase chain reaction (PCR) with a TaqMan ${ }^{\circledR}$ probe located in $C A P N 3$ exon 5: comparative threshold cycle curve ratios and SD of nine healthy control individuals, patient CT5 and her parents; note the hemizygous state for the patient and her father (arrows). (c) Identification of a genomic PCR junction fragment $\left(^{*}\right)$ in patient CT5 and her father, and sequencing of the genomic borders/breakpoints of the deletion. CT5, patient CT5; Fa, father of patient CT5; Mo, mother of patient CT5; N1, normal control; M, 100 bp ladder; Cal, calibrator sample; NTC, no-template control sample.

the ddCT ratio ranged from 0.86 to 1.02 . A ddCT ratio of 1.15 (diploid) was found for the patient's mother, whereas the patient and her father were found hemizygous (respective ddCT values of 0.55 and 0.50 ), thus confirming the hypothesis of a large-sized genomic deletion in the patient, inherited from her father.

We determined the genomic borders/breakpoints of this deletion using long-range PCR. A $\sim 6 \mathrm{kbp}$ junction fragment was first obtained in the father of the patient (with a forward primer located $5^{\prime}$ of exon 1 and a reverse primer located $3^{\prime}$ of exon 9, data not shown). We sequenced this junction fragment, and then 'walked' with internal primers. One particular reverse primer (5'AATGGGTTCTGGACATAGACA3') in IVS8 revealed the genomic junction. This was further confirmed in the patient with internal/ nested primers (forward 5'GACCAGCACATGGTTGAGTG3' and reverse 5'GAT-
GCAGCAAAGGGAATCTC3'), amplifying a shorter PCR junction fragment (Fig. 2c). Sequencing of this fragment confirmed the genomic junction joining IVS1 to IVS8 (g.309 + 4469 c.1116-1204del) (Fig. 2c).

This deletion was neither retrieved in patients CT2 and CT4 nor in 18 additional patients suspected of being affected with LGMD2A, for whom only one or no $C A P N 3$ mutation had been identified and for whom no muscle tissue was available for cDNA analysis. However, as this deletion has been previously reported in three patients $(16,27,28)$, it should be interesting to evaluate whether it constitutes a recurrent mutation or an ancestral mutated allele.

Some possible LGMD2A patients with only one or no identified $C A P N 3$ disease-causing mutation may carry partial $C A P N 3$ gene deletions or duplications. In particular, in this study, cDNA analysis in patients CT2 and CT4 obviated, 
(a)

CAPN3 gene
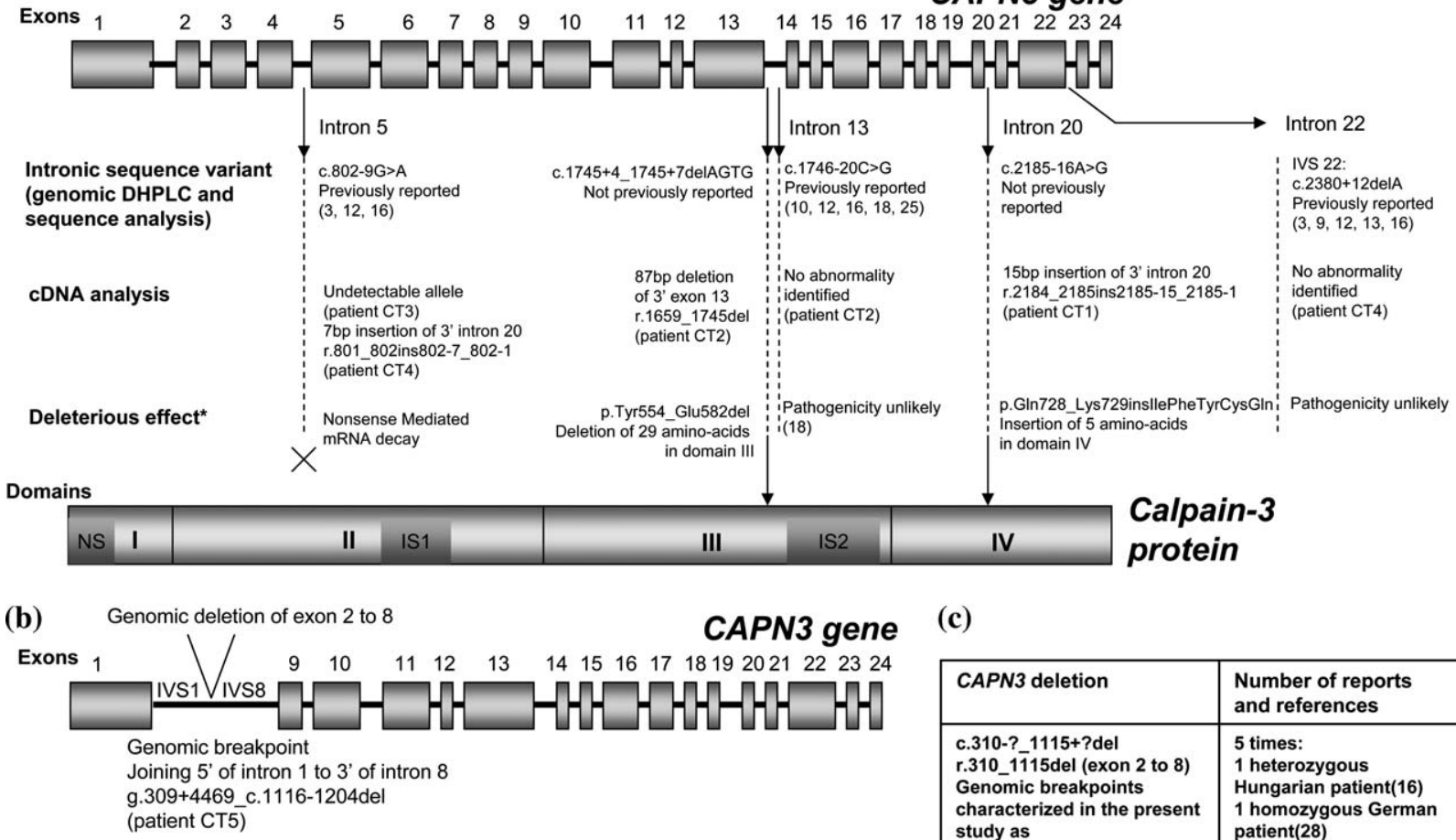

(c)

\begin{tabular}{|l|l|}
\hline CAPN3 deletion & $\begin{array}{l}\text { Number of reports } \\
\text { and references }\end{array}$ \\
\hline $\begin{array}{l}\text { c.310-?_1115+?del } \\
\text { r.310_1115del (exon 2 to 8) } \\
\text { Genomic breakpoints } \\
\text { characterized in the present } \\
\text { study as }\end{array}$ & $\begin{array}{l}5 \text { times: } \\
1 \text { heterozygous } \\
\text { Hungarian patient(16) } \\
1 \text { homozygous German } \\
\text { patient(28) }\end{array}$ \\
& $\begin{array}{l}\text { 2heterozygous Bulgarian } \\
\text { patients(27) } \\
1 \text { heterozygous French } \\
\text { patient, this study }\end{array}$ \\
\hline $\begin{array}{l}\text { c.632+404_1116-1204del } 1029+? d e l \\
\text { r.633_1029del (exon 5 to 7) }\end{array}$ & $\begin{array}{l}2 \text { times: } \\
1 \text { heterozygous basque } \\
\text { patient(9) } \\
1 \text { heterozygous patient } \\
\end{array}$ \\
& recorded by Saenz and \\
& colleagues(16) \\
\hline
\end{tabular}

Fig. 3. (a) Effect of intronic variants, identified at the complementary DNA (cDNA) level in this study. (b) Consequence of the large-sized deletion at the genomic level. (c) Large exonic deletions described in the CAPN3 gene. Representation of introns is not to scale. *Effects on the amino acid sequence are predicted from the cDNA sequence.

respectively, only one clearly pathogenic mutation. A large genomic rearrangement in trans, but different from the deletion identified in patient CT5, is a hypothesis to be further evaluated. To date, no exonic duplications and only two different exonic $C A P N 3$ deletions have been identified (Leiden Muscular Dystrophy pages database $(9,16,25-$ 27) (Fig. 3c), probably because routine mutation detection techniques (i.e. single strand conformation polymorphism analysis, DHPLC or direct sequencing) cannot detect large genomic rearrangements. Our report further illustrates the existence of large exonic $C A P N 3$ deletions. Genomic rearrangements may be identified by cDNA analysis (i.e. deletions of one or several exons), leading to an orientated genomic analysis (9). However, a more systematic approach using quantitative multiplex PCR of short fluorescent fragments (28) and/or multiplex ligation-dependent probe amplification (29) should be developed for more cost-effective and routine-based screening.
For exhaustive mutational screening in LGMD2A patients, a combinatory genomic and transcriptional approach should ideally be used and allow for the detection of both disease-causing mutations in most patients (including novel intronic mutations and large genomic rearrangements), accurate diagnosis and genetic counselling.

\section{Supplementary material}

Table S1. RT-PCR conditions, primer pairs and amplified regions of the $C A P N 3$ cDNA used in this study.

Fig. S1. CAPN3 muscle cDNA sequencing in patients CT1 and CT2. Forw, forward sequence; Rev, reverse sequence.

Supplementary materials are available as part of the online article at http://www.blackwell-synergy.com/.

\section{Acknowledgements}

The authors are extremely grateful to patients and families for their invaluable cooperation. The authors thank El Hadi Hammouda, Marc Bartoli, Amets Saenz and Adolfo Lopez 


\section{Krahn et al.}

de Munain for providing helpful information. This study was supported in part by the Assistance Publique des Hôpitaux de Marseille, the French network for molecular exploration of neuromuscular disorders (DHOS/OPRC $\mathrm{N}^{\circ} 02707$ ) and the Association Française contre les Myopathies.

\section{References}

1. Chiannilkulchai N, Pasturaud P, Richard I, Auffray C, Beckmann JS. A primary expression map of the chromosome $15 \mathrm{q} 15$ region containing the recessive form of limbgirdle muscular dystrophy (LGMD2A) gene. Hum Mol Genet 1995: 4: 717-725.

2. Richard I, Broux O, Allamand V et al. Mutations in the proteolytic enzyme calpain 3 cause limb-girdle muscular dystrophy type 2A. Cell 1995: 81: 27-40.

3. Krahn M, Lopez de Munain A, Streichenberger $\mathrm{N}$ et al. CAPN3 mutations in patients with idiopathic eosinophilic myositis. Ann Neurol 2006: 59: 905-911.

4. Sorimachi $\mathrm{H}$, Imajoh-Ohmi S, Emori $\mathrm{Y}$ et al. Molecular cloning of a novel mammalian calcium-dependent protease distinct from both $\mathrm{m}$ - and mu-types. Specific expression of the mRNA in skeletal muscle. J Biol Chem 1989: 264: 20106-20111.

5. Kramerova I, Kudryashova E, Venkatraman G, Spencer MJ. Calpain 3 participates in sarcomere remodeling by acting upstream of the ubiquitin-proteasome pathway. Hum Mol Genet 2005: 14: 2125-2134.

6. Duguez S, Bartoli M, Richard I. Calpain 3: a key regulator of the sarcomere? FEBS J 2006: 273: 3427-3436.

7. Urtasun M, Saenz A, Roudaut C et al. Limb-girdle muscular dystrophy in Guipuzcoa (Basque Country, Spain). Brain 1998: 121 (Pt 9): 1735-1747.

8. Chou FL, Angelini C, Daentl D et al. Calpain III mutation analysis of a heterogeneous limb-girdle muscular dystrophy population. Neurology 1999: 52: 1015-1020.

9. Richard I, Roudaut C, Saenz A et al. Calpainopathy a survey of mutations and polymorphisms. Am J Hum Genet 1999: 64: 1524-1540.

10. Krahn M, Bernard R, Pecheux $\mathrm{C}$ et al. Screening of the CAPN3 gene in patients with possible LGMD2A. Clin Genet 2006: 69: 444-449.

11. Fanin M, Fulizio L, Nascimbeni AC et al. Molecular diagnosis in LGMD2A: mutation analysis or protein testing? Hum Mutat 2004: 24: 52-62.

12. Piluso $\mathrm{G}$, Politano $\mathrm{L}$, Aurino $\mathrm{S}$ et al. The extensive scanning of the calpain-3 gene broadens the spectrum of LGMD2A phenotypes. J Med Genet 2005: 42: 686-693.

13. Saenz A, Leturcq F, Cobo AM et al. LGMD2A: genotypephenotype correlations based on a large mutational survey on the calpain 3 gene. Brain 2005: 128: 732-742.

14. Thiel CT, Kraus C, Rauch A et al. A new quantitative PCR multiplex assay for rapid analysis of chromosome 17p11.2-12 duplications and deletions leading to HMSN/HNPP. Eur J Hum Genet 2003: 11: 170-178.

15. Livak K. Comparative $\mathrm{Ct}$ method. ABI Prism 7700 Sequence Detection System. User bulletin. Foster City: PE Applied Biosystems, 1997: 11-15.

16. Leiden Muscular Dystrophy pages $\odot$ http://www.dmd.nl

17. Ravulapalli R, Garcia Diaz B, Campbell RL, Davies P. Homodimerization of calpain 3 penta-EF-hand domain. Biochem J 2005: 388: 585-591.

18. Stehlikova K, Zapletalova E, Sedlackova J et al. Quantitative analysis of CAPN3 transcripts in LGMD2A patients: involvement of nonsense-mediated mRNA decay. Neuromuscul Disord 2007: 17: 143-147.

19. Richard I, Brenguier L, Dincer P et al. Multiple independent molecular etiology for limb-girdle muscular dystrophy type 2 A patients from various geographical origins. Am J Hum Genet 1997: 60: 1128-1138.

20. de Paula F, Vainzof M, Passos-Bueno MR et al. Clinical variability in calpainopathy: what makes the difference? Eur J Hum Genet 2002: 10: 825-832.

21. Frischmeyer PA, Dietz HC. Nonsense-mediated mRNA decay in health and disease. Hum Mol Genet 1999: 8: 18931900.

22. Maquat LE. Nonsense-mediated mRNA decay: splicing, translation and mRNP dynamics. Nat Rev Mol Cell Biol 2004: 5: 89-99.

23. Kerr TP, Sewry CA, Robb SA, Roberts RG. Long mutant dystrophins and variable phenotypes: evasion of nonsensemediated decay? Hum Genet 2001: 109: 402-407.

24. Resta N, Susca FC, Di Giacomo MC et al. A homozygous frameshift mutation in the ESCO2 gene: evidence of intertissue and interindividual variation in Nmd efficiency. J Cell Physiol 2006: 209: 67-73.

25. Hermanova M, Zapletalova E, Sedlackova J et al. Analysis of histopathologic and molecular pathologic findings in Czech LGMD2A patients. Muscle Nerve 2006: 33: 424-432.

26. Pollitt C, Anderson LV, Pogue R et al. The phenotype of calpainopathy: diagnosis based on a multidisciplinary approach. Neuromuscul Disord 2001: 11: 287-296.

27. Todorova A, Georgieva B, Tournev I et al. A large deletion and novel point mutations in the calpain 3 gene (CAPN3) in Bulgarian LGMD2A patients. Neurogenetics 2007: 8: 225-229.

28. Joncourt F, Burgunder J, Steinlin M, Gallati S. LGMD2A caused by a large deletion: clinical, histochemical and molecular analysis. Eur J Hum Genet 2003: 11 (Suppl. 1): 667.

29. Casilli F, Di Rocco ZC, Gad S et al. Rapid detection of novel BRCA1 rearrangements in high-risk breast-ovarian cancer families using multiplex PCR of short fluorescent fragments. Hum Mutat 2002: 20: 218-226.

30. Schouten JP, McElgunn CJ, Waaijer $\mathrm{R}$ et al. Relative quantification of 40 nucleic acid sequences by multiplex ligation-dependent probe amplification. Nucleic Acids Res 2002: 30: e57. 